\title{
O FORTALECIMENTO DO CLIENTE: ALTERNATIVA PARA A VALORIZAÇÃO DAS BIBLIOTECAS PÚBLICAS EM UM AMBIENTE DE INFORMAÇÃO ELETRÔNICA
}

\section{WALDOMIRO VERGUEIRO}

\begin{abstract}
Resumo
Analisa as características de um ambiente no qual a informação eletrônica ocupará papel cada vez mais preponderante. Discute as perspectivas de atuação das bibliotecas públicas nesse novo ambiente. Propõe a valorização dos clientes nos serviços de biblioteca pública como uma alternativa possível para o fortalecimento do papel social dessa instituição.
\end{abstract}

\section{Palavras-Chave}

Bibliotecas públicas. Informação eletrônica. Cliente.

\section{Introdução}

Este é um tempo de grandes mudanças, principalmente na área de serviços de informação. Quase todos os dias é possível ouvir afirmações que fazem a previsão de um mundo no qual a informação será transmitida apenas eletronicamente e no qual todos os documentos produzidos em suporte papel não passarão de lembrança. Neste novo ambiente louvado pelos entusiastas da informação eletrônica, a informação irá fluir até seus interessados de uma maneira quase que instantânea, ao simples apertar de um mouse de computador. Bastará isso, dizem, para que a informação desejada surja na tela do computador, pronta para ser utilizada. E assim, sem esforço, com a maior naturalidade do mundo, será possível participar deste admirável mundo novo da informação eletrônica (Evans, p.2, 1995).

De fato, existem razões para acreditar que um novo e maravilhoso mundo espera a todos ao virar deste século. Na história do mundo, as mudanças, não apenas as tecnológicas mas também sociais, jamais ocorreram em ritmo tão avassalador como as de agora. Da mesma forma, idéias tradicionalmente aceitas como verdades absolutas passam a ser contestadas. Perspectivas diferentes surgem a partir de antigas proposições. A ampliação de possibilidades parece ser a única constante a marcar a contemporaneidade.

Especificamente na área da informação, a passagem "da biblioteca baseada em papel para a biblioteca automatizada em um período de cerca de duas décadas" (Shaughnessy, 1996, p. 49), 
representou uma experiência de tirar o fôlego até mesmo dos mais otimistas quanto ao avanço da tecnologia. Um avanço que, diga-se de passagem, parece ainda estar longe de seu término.

Mas é também uma época de paradoxos: ao mesmo tempo que se prenuncia o fim das publicações em formato papel, países desenvolvidos como França e Inglaterra orgulham-se em apresentar ao mundo seus recém-contruídos edifícios para abrigar suas bibliotecas nacionais. São prédios modernos, enormes e suntuosos, que parecem tornar evidente muito mais do que uma opção arquitetônica: ao inaugurá-los, esses países, talvez até mesmo inconscientemente, demonstram sua descrença na biblioteca sem muros que alguns autores prenunciam (Ardis, 1994; Chartier, 1994). Afinal, se não existirão livros no futuro, para que construir os prédios que os deverão armazenar?

No entanto, paradoxos à parte, pode-se encontrar argumentos em apoio ao estado de otimismo reinante quanto às novas tecnologias da informação eletrônica. Como considerar negativamente uma realidade na qual os indivíduos terão acesso a todas as informações de que necessitem realmente (ou mesmo àquelas de que jamais irão ter necessidade alguma)? Como renegar as possibilidades que isso oferece em termos de fortalecimento da cidadania? $\mathrm{E}$, ainda mais, como justificar a oposição a tais melhorias sociais sem descambar para o reacionarismo?

Deve-se também tomar um certo cuidado em relação às possibilidades da informação eletrônica. Oexcesso de entusiasmo quanto às implicações que, neste final de século, a globalização da informação irá ter sobre as atividades das bibliotecas e centros de informação, pode fazer com que se perca a perspectiva correta para análise desse fato social. E perder essa perspectiva pode significar duas coisas: 1) a subestimação das possibilidades que os novos meios eletrônicos abrem para instituições de informação dos mais variados tipos; e, 2) a nãodefinição de estratégias para atuação e sobrevivência institucional na nova realidade dos serviços de informação, que deverá predominar em um futuro talvez não tão distante assim. Este artigo busca discutir algumas dessas implicações, abordando especificamente a realidade das bibliotecas públicas. Além disso, apresenta a proposta da valorização do serviços ao cliente como uma alternativa viável para o fortalecimento tanto das instituições como dos próprios profissionais que atuam na área.

\section{0 novo ambiente da informação eletrônica}

Em relação às atividades de armazenamento, recuperação e disseminação da informação, nem tudo pode ser visto como definitivamente estabelecido. Algumas das previsões que apontam para a perspectiva de um futuro sem livros ou bibliotecas, pelo menos como hoje as conhecemos, podem e devem ser questionadas, na medida em que muitas vezes caem em um simplismo exagerado.

É certo que o aparecimento das bibliotecas virtuais pode já ser dado como certo, mas provavelmente elas serão uma entre as muitas alternativas para obtenção de informação disponíveis aos habitantes do Século XXI. Não, absolutamente, a única. Entre essas várias alternativas, é possível, como faz Tefko Saracevic, 
acreditar na permanência das bibliotecas e, ao mesmo tempo, reconhecer que elas deverão se modificar:

A grande questão para as bibliotecas é que as bibliotecas não vão desaparecer. As bibliotecas são instituições maravilhosamente estáveis que provaram sua existência por mais de 2000 anos: a primeira biblioteca que nós conhecemos foi a de Assurbanipal em 600 a.C. Existem bibliotecas em toda cultura que tenha a escrita e elas desempenharam um papel cultural fantástico; elas são um signficante tronco social. Elas vão ainda desempenhar esse papel mas elas vão fazer coisas diferentes. A grande questão hoje é como balancear isto com seu papel tradicional que tem a ver com o impresso. A impressão não vai desaparecer - existem mais livros impressos agora do que nunca antes na história da humanidade, por isso eles não vão desaparecer, mas eles terão que balancear com este aspecto digital (1996, p. 518).

Autores como Crawford e Gorman (1995, p. 18), Hagloch (1996, p. 150) e Woodward (1995, p. 18), entre outros, têm basicamente a mesma opinião de Saracevic, defendendo a adequabilidade do livro tradicional a muitas das funções para as quais foi originalmente criado como uma das grandes razões para seu nãodesaparecimento. E, pode-se concluir, na medida em que se acredita na permanência do livro impresso, é também possível acreditar que o mesmo acontecerá com as instituições às quais ele tradicionalmente esteve umbilicalmente ligado, as bibliotecas e, mais modernamente, os centros de documentação e informação.
Outro ponto que merece ser considerado em relação ao novo ambiente da informação que existirá no próximo século diz respeito ao contexto social existente atualmente, por enquanto excessivamente dominado pela informação impressa. Já durante vários séculos, a informação em suporte papel vem garantindo a seus usuários um nível de confiabilidade bastante grande, nível esse ainda longe de ser atingido pela informação eletrônica. Esta última carece de indicadores que permitam concluir pela confiabilidade da informação obtida: a probabilidade de qualquer pessoa intervir no processo de criação e disponibilização da informação, refazendo a idéia veiculada, adulterando-a, modificando-a e distribuindo-a segundo seus próprios interesses representa uma variável não passível de controle pela tecnologia atual. Segundo Floridi (1996, p. 510), é grave a possibilidade de difusão de desinformação nas redes eletrônicas, devido, principalmente, à "crescente facilidade e velocidade com que documentos mono ou multimídia podem ser criados, manipulados, reproduzidos e distribuídos". Ainda segundo esse autor, a possibilidade de desinformação só será minimizada quando forem desenvolvidos instrumentos que permitam monitorar a informação disponível de forma eletrônica e, desta forma, assegurar:

(1) a confiabilidade, integridade e pluralidade da informação digital;

(2) constante acesso ao macrocosmo digital para o maior número de pessoas (direito universal à produção e uso da informação); (3) um mapa constantemente atualizado do universo digital de informação disponível online (Floridi, 1996, p. 511). 
Ligado ao ponto acima mencionado estão questões que dizem respeito à compensação pecuniária do autor da informação eletronicamente disponibilizada. Não se deve ser ingênuo a ponto de acreditar que as motivações de lucro e reconhecimento intelectual que moveram a indústria editorial pós-gutemberguiana durante seis séculos deixarão de existir na realidade da informação eletrônica. Tanto autores como editores continuarão a buscar o lucro, os primeiros talvez mostrando uma ânsia maior nesse objetivo do que os segundos. A idéia de que o verdadeiro artista irá se comprazer com a simples possibilidade de ter sua arte veiculada eletronicamente parece no mínimo infantil. Artistas, como todas as demais pessoas da face da Terra, também precisam garantir sua sobrevivência. $\mathrm{Ou}$, se não quisermos ir tão longe: necessitam de incentivos materiais que lhes permitam continuar produzindo sua arte. Eé importante constatar que, neste sentido, a informação eletrônica ainda está aparentemente bastante longe de oferecer uma resposta satisfatória (Gasaway, 1996a). Da mesma forma, a própria questão do direito moral de autor está também distante de um equacionamento satisfatório, bem como a utilização da informação eletrônica em contextos educacionais, de crítica, jornalísticos, etc., tradicionalmente cobertos pela prática conhecida como fair use (Gasaway, 1996b).

Por outro lado, não se deve também perder de vista o elemento ideológico que muitas vezes é sorrateiramente acrescentado à análise das tecnologias de informação eletrônica e seu papel no mundo contemporâneo. Como afirma Lopez (1996, p. 10), "não há nenhum motivo para pensar que as "auto-estradas da informação" revolucionarão o mercado de trabalho (em sentido positivo)". Verifica-se, assim, que a imagem de um trabalhador feliz e satisfeito que realiza suas atividades profissionais sem sair de sua própria residência, por intermédio de computadores, tem muito de enganadora. Ainda nas palavras de Lopez (1996, p. 10): "para cada emprego criado em associação com o setor da informação, provavelmente se estão perdendo dois empregos "clássicos"”.

Com certeza, muita coisa mudará no ambiente de informação em que as bibliotecas tradicionalmente predominaram, redimensionando algumas das atividades desenvolvidas pelos bibliotecários, como a catalogação, a classificação e, principalmente, o desenvolvimento de coleções (Vergueiro, 1997). Afirma-se até que qualquer indivíduo, com o uso dos meios eletrônicos, poderá fazer ele mesmo o recorte do universo informacional que mais the aprouver, ou seja, buscar as informações nas redes eletrônicas e organizá-las segundo seus interesses e perspectivas pessoais. De fato, isto realmente poderá ocorrer, em certa medida até bastante rapidamente. No entanto, por mais que se queira louvar as benesses do mundo digital, talvez ainda esteja longe o dia em que se poderá prescindir de um intermediário que, nessa área, atue como o elemento de ligação entre o imenso universo do conhecimento registrado e seus interessados. Neste sentido, Crawford e Gorman (1995, p. 108) fazendo a analogia dos serviços de informação com os de mecânica, afirmam que "mesmo aceitando que a maioria dos adultos poderia aprender a fazer o conserto de seus próprios carros, encanamento, e trabalho elétrico - uma pressuposição que levaria a um mundo até mais perigoso do que o de hoje por que diabos o fariam?" 
Não existem ainda certezas se o panorama da informação irá encaminhar-se realmente para o cenário de total independência e acesso direto defendido por autores como Negroponte (1995) ou Gates, Myhrvold \& Rinearson (1995). De qualquer forma, com a possibilidade concreta de acessar diretamente as informações, o indivíduo terá a possibilidade de optar entre este acesso e a utilização de um intermediário, alguém ou alguma instituição que realize todo o trabalho de identificação de pontos de interesse e a posterior disponibilização da informação.

Com certeza, a opção pela segunda alternativa vai depender basicamente de dois fatores:

- $\quad$ a disponibilidade ou interesse do cliente em aprender a utilizar a rede eletrônica, obtendo dela o maior benefício possível;

- $\quad$ a qualidade do serviço prestado pela instituição de informação, refletida no produto obtido por seu intermédio.

Quanto ao primeiro caso, é possível pensar que, em um mundo dominado pela ansiedade da informação (Wurman, 1991), talvez seja até lógico imaginar que não será pequeno o número de pessoas interessadas em dominar as técnicas de recuperação da informação em ambiente eletrônico. Além disso, é também possível acreditar que a própria evolução dos meios eletrônicos irá concorrer para isso, na medida em que poderá torná-los instrumentos cada vez mais amigáveis, com uma facilidade de manuseio bastante próxima à de uma lista telefônica bem organizada. Por outro lado, isto não significa que, necessariamente, todos os usuários da Superestrada da Informação vão fazer isso. Pode-se imaginar que a própria comodidade dos indivíduos poderá concorrer para a utilização dos serviços de informação: para muitos, será mais cômodo utilizar um intermediário do que a realização da busca pessoalmente. A pouca disponibilidade de tempo para buscas mais minuciosas de informação, que às vezes representam uma considerável carga de trabalho, também poderá ajudar nesse sentido. Por outro lado, é possível também imaginar que a preferência pela utilização dos serviços da biblioteca possa ocorrer em função de características intrínsecas aos resultados obtidos por seu intermédio, que apresentariam um nível de especificidade, precisão e legibilidade da informação - qualidade, enfim! - que dificilmente seria atingido se o próprio interessado houvesse realizado a busca. Ao optar pela intermediação, o indivíduo estaria visando a maximização dos resultados, a partir do valor agregado à informação quando ele a obtém via biblioteca. As instituições que souberem explorar melhor esta busca de excelência sairão na frente na disputa pela preferência de seu público.

\section{0 fortalecimento do cliente nas instituições de informação}

O ambiente sócio-cultural da informação que se descortina para o início do próximo século será cada vez mais influenciado por elementos de alta competividade e produtividade. Nele, a informação desejada deverá estar disponível, seja em que suporte for, no momento mesmo em que o cliente dela necessitar e a um custo que para ele pareça conveniente, quando tiver que arcar pessoalmente com ele (custo, neste caso, incluindo não apenas o pagamento direto em espécie mas também em termos de tempo, esforço e dificuldades que ele tem 
que enfrentar para obtenção dessa informação). E mesmo isso talvez não seja suficiente como garantia de satisfação: será necessário ir além das próprias expectativas do cliente, encantando-os com o oferecimento de serviços com um nível de qualidade superior àquele que ele esperava obter. Usando-se a terminologia atual, pode-se afirmar que só sobreviverão aquelas instituições de informação que conseguirem demonstrar de maneira inequívoca que agregam valor ao produto informacional fornecido. Este raciocínio é válido tanto para aqueles produtos que se consubstanciam em uma lista de indicações bibliográficas, como aqueles que se limitam à enunciação de um ou mais dados fatuais, e, também, àqueles que representam um simples encaminhamento para outro fornecedor de serviços de informação. O cliente deverá sentir que está ganhando algo com os serviços da biblioteca, que algo lhe foi acrescentado em termos de valor. Se ele não se convencer disso, procurará outro fornecedor (ou utilizará a independência que lhe permitem as redes de informação eletrônica).

É possível inferir, portanto, que o caminho para a permanência de instituições de informação entenda-se, bibliotecas - em um ambiente em que a informação eletrônica ocupará papel de destaque, é exatamente o de fornecer serviços que atendam os requisitos de excelência definidos pelos clientes. Será este o principal fator a levar um cidadão a utilizar os serviços de uma biblioteca como elemento intermediário para atendimento de suas necessidades informacionais, seja pela rede eletrônica, seja pelos instrumentos impressos tradicionalmente disponíveis para o fornecimento de informações.

De uma maneira geral, o mundo da produção e de serviços há muito já descobriu a necessidade de valorizar o cliente como forma de suplantar-se à concorrência. Esta é uma necessidade que se torna a cada dia mais premente, na medida em que para os próprios clientes ficam evidentes os seus direitos enquanto consumidores e cidadãos, num movimento de conscientização que tem características internacionais e do qual, felizmente, não parece haver retorno possível (e que no Brasil encontra no Código de Defesa do Consumidor, aprovado nos anos 90, sua expressão mais concreta).

Nenhuma organização da área de informação estará acima dessa tendência. Ainda que se possa acreditar que algumas instituições de informação sentirão antes de outras as pressões para priorizar o cliente dos serviços em suas atividades cotidianas, cedo ou tarde essa realidade se fará presente para todas elas. De uma certa forma, é até natural que essas pressões ocorram de maneira não-uniforme, pois o mesmo também acontece com a incorporação das tecnologias de informação à sociedade. Assim como é viável esperar que as bibliotecas ligadas ao suporte à pesquisa científica, principalmente em pesquisa de ponta, sejam as primeiras a receber as benesses da informação eletrônica, também se deve esperar que sejam elas as primeiras a serem cobradas por isso.

As bibliotecas públicas provavelmente estarão no outro lado do processo, constituindo as últimas a serem incorporadas ao novo ambiente. $\mathrm{E}$ isto talvez seja até bom, pois terão oportunidade de se preparar com mais cuidado para ele, organizando-se estrutural e culturalmente para as mudanças que se farão necessárias. Este preparo se faz ainda mais importante quando se pensa que a mudança irá envolver não apenas a implementação 
de tecnologias, mas também a modificação da própria cultura organizacional, que, em última análise, é o que representará a priorização do cliente como elemento determinador dos serviços recebidos.

\section{As bibliotecas públicas e o compromisso com os clientes}

Felizmente, os profissionais de informação que atuam em bibliotecas públicas não precisarão partir do zero para a definição de metodologias que possibilitem a sublimação do cliente, pois a literatura de administração vem oferecendo nos últimos anos uma grande variedade de possibilidades cujos benefícios já foram suficientemente testados e comprovados. Trabalhos como os de Karl Albrecht (1993, 1994) e Tom Peters (1993) podem proporcionar um bom ponto de partida para uma mudança organizacional centrada no cliente dos serviços de informação. Internacionalmente, o trabalho desses autores já vem sendo utilizado pelos profissionais responsáveis por esses serviços, podendo-se já encontrar na literatura especializada em Biblioteconomia e Ciência da Informação um bom número de títulos que defendem uma preocupação sistemática com o cliente como a melhor, senão a única, alternativa para a melhoria dos serviços e continuidade das instituições de informação. Dos autores que tratam dessa questão, pode-se destacar, entre outros, Barter (1994), Hernon \& Altman (1995) e St. Clair (1993).

No entanto, a questão não se limitará à definição de critérios pessoais de custo-benefício, que ocorreriam apenas do lado do interessado na obtenção de informações. Também os profissionais das bibliotecas públicas deverão refinar seus processos de trabalho, de modo a neles incorporar as características específicas dos clientes e do próprio meio ambiente no qual os serviços de informação se localizam. Isto significa dizer, por exemplo, que, em uma região onde os serviços de comunicação são ainda insatisfatórios devido a congestionamentos freqüientes, quedas de linha e dificuldades básicas de manutenção, a opção pela disponibilização de informações via redes eletrônicas pode ser preterida por sua obtenção pelos meios tradicionais impressos, de modo a evitar queixas e frustração dos clientes em relação aos serviços recebidos.

Por outro lado, a questão não pode ser vista apenas sob o ponto de vista da adoção de uma nova tecnologia. Trata-se, isso sim, de uma reestruturação da forma de atuação das bibliotecas públicas, colocando-se o cliente dos serviços como o centro da própria razão de ser das instituições. É esta provavelmente sua única garantia de sobrevivência.

Sob muitos aspectos, representa ainda uma incógnita a forma como esse compromisso com o cliente irá transformar-se em uma realidade incorporada à cultura das bibliotecas públicas. A simples mudança de denominação - de usuário para cliente, - tem que significar muito mais do que a opção por uma terminologia mais moderna. Deve, isto sim, representar a opção por um modelo de gestão que visa transformar a "organização numa entidade voltada para o serviço e motivada pelo atendimento do cliente (Albrecht, 1994, p. 23). 
Isto exigirá um investimento muito grande tanto no nível pessoal como no institucional. No nível pessoal, implicará no comprometimento de cada profissional das bibliotecas públicas na priorização dos serviços aos clientes. No nível institucional, exigirá que os responsáveis pela administração dos serviços dessas bibliotecas, nas esferas superiores da administração pública, firmem o mesmo compromisso com o cliente, realizando efetivo investimento no treinamento e capacitação profissionais de seus funcionários, condição essencial para que o nível de excelência dos serviços possa ser ampliado aos níveis de excelência desejados. Só por isso, já é possível perceber que o caminho para a mudança não será absolutamente fácil.

Sob outro enfoque, no entanto, pode-se começar o processo de valorização do cliente firmando-se compromissos reais e viáveis de atendimento. Em outras palavras, informando à clientela da biblioteca pública para que esta existe e o que ela se propõe a fazer. Deixando claro para ela o que pode esperar obter da biblioteca e como deve agir quando não conseguir fazê-lo. Comprometendo-se a levar sua opinião em consideração na definição de seus processos de trabalho e, caso não seja possível fazê-lo, explicar porque isso aconteceu. Garantindo que considerará suas eventuais queixas e reclamações como possibilidades de melhoria a serem apreciadas e valorizadas.

É esse o caminho que vêm seguindo muitas bibliotecas públicas, bem como outras instituições responsáveis por serviços ao público, como hospitais, creches, escolas, postos de saúde, etc., de países mais desenvolvidos, que estabelecem compromissos de atendimento de seus clientes e esforçam-se sinceramente por cumprí-los. Conhecidos como Citizen's charters ou Library Users Charters, esses compromissos constituem declarações de intenções dos diversos serviços, esclarecendo seus clientes sobre os benefícios que pretendem trazer às suas vidas. Trata-se, normalmente, de "um documento breve, escrito do ponto de vista do cliente (Wehmeyer, Auchter \& Hirshon, p. 175, 1996).

O Reino Unido é, talvez, o país em que o conceito de Citizen's charters encontra-se em maior evidência nas bibliotecas públicas, acompanhando uma tendência geral de priorização do cliente nos serviços públicos ingleses e tentando fazer com que as organizações governamentais prestem contas de seus atos (Ford, 1996). A biblioteca pública do Condado de Kent, por exemplo, entre seus compromissos com os clientes estabeleceu:

Nós estamos aqui para:

Fornecer livros em empréstimo para adultos e crianças em pontos de serviço convenientes.

Fornecer material audio-visual, tais como audio cassetes, vídeos e músicas em cassete, compact discs e cursos de línguas, em todas as bibliotecas centrais.

Atender as necessidades das minorias étnicas, pessoas com deficiências físicas e outros clientes com necessidades particulares (Kent County Council, 1992).

Já o Real Condado de Berkshire estabeleceu compromissos específicos para suas bibliotecas públicas de acordo com o tamanho da população a que cada uma delas deverá servir. Assim, horários Inf.Inf., Londrina, v.1, n.2, p.7-18, jul./dez. 1996 
de funcionamento, porcentagem de livros disponíveis para empréstimos, etc. irão variar de acordo com uma classificação de serviços mínimos estabelecida pelo Condado. Em bibliotecas maiores, essa garantia de serviços é formulada da seguinte forma:

Nós garantimos que estas bibliotecas estarão abertas pelo menos 40 horas por semana, incluindo todos os sábados e duas noites.

Nós garantimos que o acervo terá os 100 autores mais emprestados.

Nós garantimos que pelo menos $45 \%$ dos livros de empréstimo para adultos serão livros de não-ficção (Royal County of Berkshire, 1993).

E a lista de exemplos poderia continuar por muitas páginas mais, abrangendo desde compromissos relacionados com o tempo de espera de não mais de três minutos em filas para atendimento nas bibliotecas (Brent Council, 1993) à promessa de responder em três dias, por escrito ou por via telefônica, a todas as reclamações feitas em relação aos serviços das bibliotecas (Southwark Council, 1994). Todas elas representam a busca de fortalecimento do papel do cliente nas bibliotecas públicas, demonstrando claramente para o público que a instituição está empenhada em atingir a completa satisfação de suas necessidades.

Por outro lado, é importante salientar que os exemplos acima mencionados são apenas ilustrativos de uma nova mentalidade de serviço e não visam sua aplicação em realidades diferentes daquelas para as quais foram originalmente elaborados. É claro que não se poderá exigir de bibliotecas públicas brasileiras, por exemplo, um nível de comprometimento semelhante àquele no qual se engajaram as bibliotecas de países mais desenvolvidos. A realidade brasileira é outra, provavelmente muito mais perversa em termos de infra-estrutura e disponibilidade de recursos financeiros do que aquela vivida pelas bibliotecas desses países. No entanto, entende-se que algum tipo de compromisso, ainda que inicialmente modesto, tem condições de ser feito. Neste sentido, cada biblioteca pública deverá analisar suas capacidades e possibilidades, buscar ouvir seus clientes e firmar seus compromissos em consonância com todos os fatores envolvidos em sua prestação. Importante salientar, nesse aspecto, que qualquer tipo de comprometimento deverá ser feito somente quando existir razoável nível de certeza de que haverá realmente possibilidade efetiva de que ele possa ser cumprido. Na dúvida, é prudente comprometer-se com menos, evitando criar falsas expectativas e frustrar os clientes, colocando em risco todo o processo de melhoria dos serviços que se almeja atingir.

\section{Conclusão}

Ao entrar no novo ambiente que se descortina para os serviços de informação em geral, um ambiente que provavelmente será marcado pela convivência entre a informação eletrônica e aquela conservada em suporte papel, as bibliotecas públicas deverão viver um momento de competitividade como nunca antes viveram. Correm o risco de se tornarem desnecessárias em um mundo no qual o fornecimento de informação deverá ocorrer cada vez mais no momento em que o cliente dele necessita, sendo inaceitáveis os atrasos, as procrastinações e as justificações pelo não fornecimento. Poderão inclusive, caso não se preparem convenientemente, caminhar mais rapidamente para sua 
descaracterização enquanto instituições provedoras de informação. Apenas se conseguirem demonstrar para sua clientela que sua atividade profissional representa valor agregado à informação que fornecem é que poderão caminhar tranqüilas em direção ao futuro.

É quase obrigatório concluir que esse acréscimo de valor acima mencionado resultará, em um primeiro momento, da consideração diretamente dada às características da clientela/comunidade que deve ter suas necessidades satisfeitas pela instituição de informação. No entanto, é também importante ter em mente que esse acréscimo não se esgotará apenas no trabalho inicial de seleção e/ou encaminhamento à informação desejada, por intermédio da mídia eletrônica, mas se ampliará ou diminuirá de maneira dinâmica, na medida em que o fortalecimento do cliente se estabelecer como a base sobre a qual se alicerçam a filosofia, a missão e a visão das bibliotecas públicas. Considerando as diversas barreiras organizacionais, educacionais, psicológicas e sociais que representam muitas vezes a rotina dessas instituições no país, é fácil concluir que o caminho terá muito mais pedras do que areia macia. Mas, infelizmente, não parecem existir muitas outras opções disponíveis. Levando mais longe a alegoria bíblica: ou se caminha pela pedras, o que provavelmente significa ferir os pés mas ao final atingir alguma paisagem agradável, ou absolutamente não se caminha e se acata o desaparecimento da instituição em toda a sua cruel inexorabilidade.

\section{Referências bibliográficas}

ALBRECHT, Karl. Revolução nos serviços: como as empresas podem revolucionar a maneira de tratar os seus clientes. 2.ed. São Paulo : Pioneira, 1994.

A única coisa que importa: trazendo o poder do cliente para dentro de sua empresa. São Paulo : Pioneira, 1993.

ARDIS, Susan B. (comp.) Library without walls: plug in and go. Washington: Special Libraries Association, 1994.

BARTER. R. F., Jr. In search of excellence in libraries: the management writings of Tom Peters and their implications for library and information services. Library Management, v. 15, n. 8, p. 4-15, 1994.

BRENT COUNCIL. Library users charter. Brent Arts \& Libraries Update, p. 6, Summer 1993. CHARTIER, Roger. Bibliotecas sem muros. In: A ordem dos livros: leitores, autores e bibliotecas na Europa entre os séculos XIV e XVIII. Brasília : Ed. da Universidade de Brasília, 1994.

CRAWFORD, Walt, GORMAN, Michael. Future libraries: dreams, madness \& reality. Chicago :American Library Association, 1995.

EVANS, G. Edward. Developing library and information center collections. 3.ed. Englewood, Co : Libraries Unlimited, 1995.

FLORIDI, Luciano. Brave.Net.World: the Internet as a disinformation superhighway. The Electronic Library, v. 14, n. 5, p. 509-14, 1996.

FORD, Geoffrey. Service level agreements. The New Review of Academic Librarianship, v. 2, p. 49-58, 1996.

GASAWAY, Laura N. Libraries, educational institutions, and copyright proprietors: the first collision on the information highway. Journal of Academic Librarianship, v. 22, n. 1, p. 33744, 1996.(a)

. Universities, libraries and fair use in the digital age. The Acquisitions Librarian, n. 15, p. 69-87, 1996. (b)

GATES, Bill, MYHRVOLD, Nathan, RINEARSON, Peter. A estrada do futuro. São Paulo : Companhia das Letras, 1995.

HAGLOCH, Susan B. Info mediators still needed. Library Journal, v. 121, n. 14, p. 150-1, 1996.

HERNON, Peter, ALTMAN, Ellen. Service quality in academic libraries. Norwood, N.J. - Ablex 1995 
KENT COUNTY COUNCIL. The charter for arts \& libraries. Kent : Kent County Council, 1992.

SARACEVIC, Tefko. The end of the library as we know it? The Electronic Library, v. 14, n. 6, p. 516-9, 1996. [Apresentado no Painel "Libraries present and future: the future of the library profession]

LOPEZ, Bernat. La sociedade de la información: promesa de futuro o eslogan neoliberal? Chasqui, n. 54, p. 8-11, 1996.

NEGROPONTE, Nicholas. A vida digital. São Paulo : Companhia das Letras, 1995.

PETERS, Tom. Rompendo as barreiras da administração: a necessária desorganização para enfrentar a nova realidade. São Paulo : Harbra, c1993.

ROYAL COUNTY OF BERKSHIRE. Public libraries service guarantees. Berkshire County Council, 1993.

RUTSTEIN, Joel S., DeMILlER, Anna L, FUSELER, Elizabeth A. Ownership versus access: shifting perspectives for libraries. Advances in Librarianship, v. 17, p. 33-60, 1993.

ST. CLAIR, Guy. Customer service in the information environment. London : Bawker Saur, 1993.

SHAUGHNESSY, Thomas W. The library director as change agent. Journal of Library Administration, v. 22, n. 2/3, p. 43-56, 1996.

SOUTHWARK COUNCIL. Our commitments to you. Southwark: 1994.

VERGUEIRO, Waldomiro C. S. O futuro das bibliotecas e o desenvolvimento de coleções: perspectivas de atuação para uma realidade em efervescência. Perspectivas em Ciência da Informação, v. 2, n. 1, 1997. (no prelo)

WEHMEYER, Susan, AUCHTER, Dorothy, HIRSHON, Arnold. Saying what we will do, and doing what we say: implementing a customer service plan. Journal of Academic Librarianship, v. 22, n. 3, p. 173-80, 1996.

WOODWARD, Jeannette A. Auto aces or accident victims: librarians on the info superhighway. American Libraries, v. 26, n. 10, p. 1016-9,
1995.

WURMAN, Richard Saul. Ansiedade de informação: como transformar informação em compreensão. São Paulo : Cultura Editores Associados, 1991.

\section{Waldomiro Vergueiro}

Professor Doutor do Departamento de Biblioteconomia e Documentação da Escola de Comunicações e Artes da Universidade de São Paulo

Title 
Customer empowerment: alternative for the enhancement of public libraries in an electronic information environment

\begin{abstract}
Analyses the characteristics of an environment in which electronic information will play a promiment role. Discusses the perspectives for the work of the public libraries in this new environment. Proposes customer empowerment in public library services as a possible option for the enhancement of their social function.
\end{abstract}

\title{
Keywords
}

Public Library. Eletronic information. Users.

Artigo recebido em 25/11/96 